Case Reports

\title{
Outlook of Municipal Solid Waste in Bogota (Colombia)
}

\author{
José Alejandro Martínez Sepúlveda \\ School of Graduates, Universidad EAN, Carrera 11 78-47 Second Floor, Bogota, 110221, Colombia
}

Article history

Received: 08-01-2016

Revised: 08-02-2016

Accepted: 01-03-2016

E-mail: jamartinez@ean.edu.co

\begin{abstract}
The Municipal Solid Waste is a new target of the municipal government because their negative consequences if the management is inadequate (health diseases, pollution, etc.); In Latin America, the most frequency solution is the final disposal in landfill, but, no-all the Solid Waste is really waste (or unusable material): (i) The Inorganic Fraction that, for the no source separation, lost the use possibility in value chains and (ii) The Organic Fraction, which is produced during food processing in houses, restaurants and enterprises, has a potential uses (traditional as Compost, or new uses as matter for other process). For those, the solid waste management is a challenge in many cities on this "developing countries" as Brazil, Peru, Ecuador, Colombia or the Caribbean nations; this paper find to explain how they have handled solid waste in the capital of Colombia (Bogotá), without the landscape of all Latin America reality. The possibilities of use and valorization of Municipal Solid Waste (MSW) and the importance of the adequate management into the cities will be the new actions on many cities for to obtain economic development and a rational use of this resources.
\end{abstract}

Keywords: Solid Waste, Latin America, Management, Bogotá

\section{Introduction}

Approximately 3 billion people generate an average of $1.2 \mathrm{~kg}$ /day of Municipal Solid Waste (MSW) which leads to a global generation of about 1300 million tons/year of this grand total, Latin America, produces about 160 million tons/year (Martínez Sepúlveda and Gómez, 2013). Just as the composition of MSW varies according to the region where it is produced, so does the per capita production thereof; to be precise, in the case of Latin America it is estimated according to a World Bank report that $54 \%$ of the total MSW corresponds to organic waste or organic fraction (MB, 2012; Martínez Sepúlveda and Gómez, 2013).

The OFMSW by its composition is considered similar to a lignocellulosic material and is a waste material that usually accumulates and ends up in landfills and its storage reaches huge volumes in developing countries. Hence the fact that challenges to work on the issue of municipal solid waste in Latin American cities focus on introducing systems of efficient source separation, valuation chains and utilization including the OFMSW and appropriate management systems of the non-usable fraction so that for either landfills or for energy use, it can have a proper management.

This document will observe firstly an overview of Latin America, moving to discuss the situation in
Colombia and closing with the reality that is happening in the capital city of Colombia, Bogotá.

\section{Conceptual Framework}

\section{Municipal Solid Waste in Latin America}

According to Martínez Sepúlveda (2012), globally about 1300 million tons/year of Municipal Solid Waste (MSW) are generated, of which about 160 million correspond to Latin America. In this area, the greater amount of waste generated corresponds to organic residues followed by paper and plastic according to Martínez Sepúlveda (2013) and as shown in Fig. 1.

$$
\begin{aligned}
& \text { = Organic 54\% } \\
& \text { = Paper 16\% } \\
& \text { " Plastic 12\% } \\
& \text { = Glass 4\% } \\
& =\text { Metal 2\% } \\
& \text { = Others 12\% }
\end{aligned}
$$

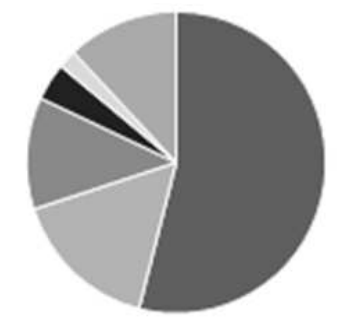

Fig. 1. Average Characterization of municipal solid waste. Source: Martínez Sepúlveda (2013) 
This situation is dynamic, because to the extent that in Latin America and the Caribbean urbanization is accentuated and population in cities increases, the amount of MSW generated is increasing at a faster pace than urbanization itself; thus not only purchasing power, but the demographics and characteristics and living conditions of the population in these cities affect the amount of waste and the characteristics there of (Martínez and Ruiz, 2015). Currently, about $54 \%$ of waste corresponds to organic fraction in the region, where only a small number is used to produce compost and animal feed (Lozano et al., 2014) or biogas (Martínez Sepúlveda and Alberto, 2013) and while that percentage will gradually decline in the future, the organic fraction of MSW continues to generate pressure on management systems and resources.

\section{Definition of Waste in Colombia}

According to document CONPES 3530, solid waste is defined as any object, material, substance or solid element resulting from the consumption or use of a good in domestic, industrial, commercial, institutional or service activities, that the generator leaves, rejects or delivers and which is subject to use or conversion into a new good, with economic value or for its final disposal (Martínez and Ruiz, 2015). In 1997 the first Policy for Waste Management is formulated in the country and from there, the classification of waste was established, which can be classified according to its characteristics-hazardous and non-hazardous and within these categories, they can be classified as usable and unusable waste, depending on type of disposal (Fig. 2).

\section{The Integrated Solid Waste Management (ISWM)}

This term applies to all activities associated with the management of various waste streams in society and its goal is to manage them in a way that is compatible with the environment and public health. The ISWM provides hierarchically defined stages: source reduction, utilization and recovery, treatment and processing, controlled disposal (Fig. 3).

\section{Waste Management in Colombia}

In Colombia, according to data from UAESP (Martínez Sepúlveda and Gómez, 2013), more than 25,000 tons/day of MSW are generated, of this amount the capital city Bogota contributes 26\%, which goes to the Doña Juana Landfill. The vast majority of the waste generated in Colombia does not have a pre-treatment before final disposal, leading to future environmental and social issues, in addition to damaging the potential of some resources found there.
Furthermore, odors arise due to the decomposition of organic matter present in the MSW that goes to landfills (Martínez et al., 2014).

About $65 \%$ of the waste that is disposed daily in the capital of Colombia corresponds to organic waste, additionally the market places in the city of Bogota generate 70 tons/day of organic waste, of which a small percentage is used for animal food and composting (Lozano et al., 2014).

The management of solid waste in the country has been made in terms of the provision of sanitation services. Concerns about waste generated in urban centers has come from considerations of hygiene and health, hence the problem is addressed from the moment that the community left the waste in the street for someone to take and at that moment came the need to establish a process of collection, no matter where this waste would go, or establishing as disposal methods outdoor disposal, or in bodies of water, without considering the external effects of such activities and the costs associated to them.

The first attempt to understand the situation of solid waste in the country, was made by the Ministry of Health, Bureau of Sanitation in 1975 and the information obtained served as the basis for formulating the National Urban Sanitation ProgramPRONASU. The assessment identified the following main problems: Low levels of coverage, use of improper equipment, absence of collection service in smaller urban centers and peripheral areas, invoicing the service as tax and not tariff, among others; it was noted that not a single urban center used a process of controlled final disposal, but they did have significant presence of efforts for the recovery of paper, cardboard, glass as container, scrap metal and bone, among the greatest elements of the market (Martínez and Ruiz, 2015).

\section{Use and Recovery of Waste in Colombia}

The use involves the separation and collection of waste materials in the place of their origin. The preparation of these materials for reuse, reprocessing, transformation into new products and the recovery of conversion products (e.g., compost) and energy in form of heat and biogas fuel. In Colombia a hierarchical integrated waste management strategy is proposed, which involves maximizing the benefits of the products, minimizing the quantity and quality (hazardousness) of waste and after putting greater emphasis on reducing waste at source, developing strategies to use (reuse, recycling and even energy recovery) of MSW, to have the least amount of waste possible (Martínez and Ruiz, 2015). 


\section{Production Chains of Materials Recovered}

The market demand for these materials is what makes that they are retrieved and classified by recyclers. The prices paid for them depends on the instance of the production chain to which they are sold; if it's a middleman, it will pay a lower value; if it's the end user, it will pay more. Another factor that affects the price is the level of processing that the material has: The more the processes (selection, compaction, washing), the greater the value; in Colombia, the chain is long in terms of the intermediaries but not in adding value to the material.

The current production chain consists of the following steps: 1 . selecting the source for the recovery and classification. 2. Storage and marketing in the Collection Center. 3. Primary Processing. 4. Industrial Transformation.

\section{Hazardous Waste in Colombia}

Hazardous waste comprise those wastes that due to their corrosive, reactive, explosive, toxic, flammable, radioactive or infectious characteristics may cause risk to human health and the environment. Hazardous materials are as well the packaging, containers and covers that have been in contact with them (Martínez and Ruiz, 2015), considering that for their characteristics that some may or not be used, without neglecting the risks intrinsic to their hazard and the importance in the prevention of the generation.

Currently, utilization and recovery practices of Hazardous waste in Colombia are in development: Between the most common waste being used we find: Lubricating oils, used as fuel; the used acid-Lead batteries, which are recycled for manufacturing new batteries; developing liquids used for silver recovery; recovery of spent solvents, among others.

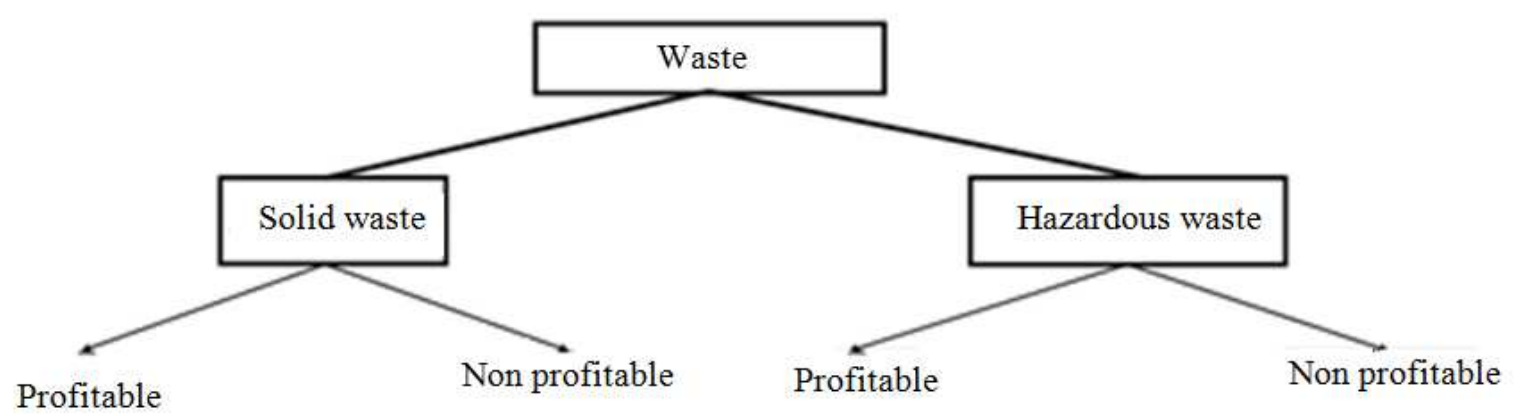

Fig. 2. Classification of solid waste. Source: Policy for Integrated Waste Management, 1997

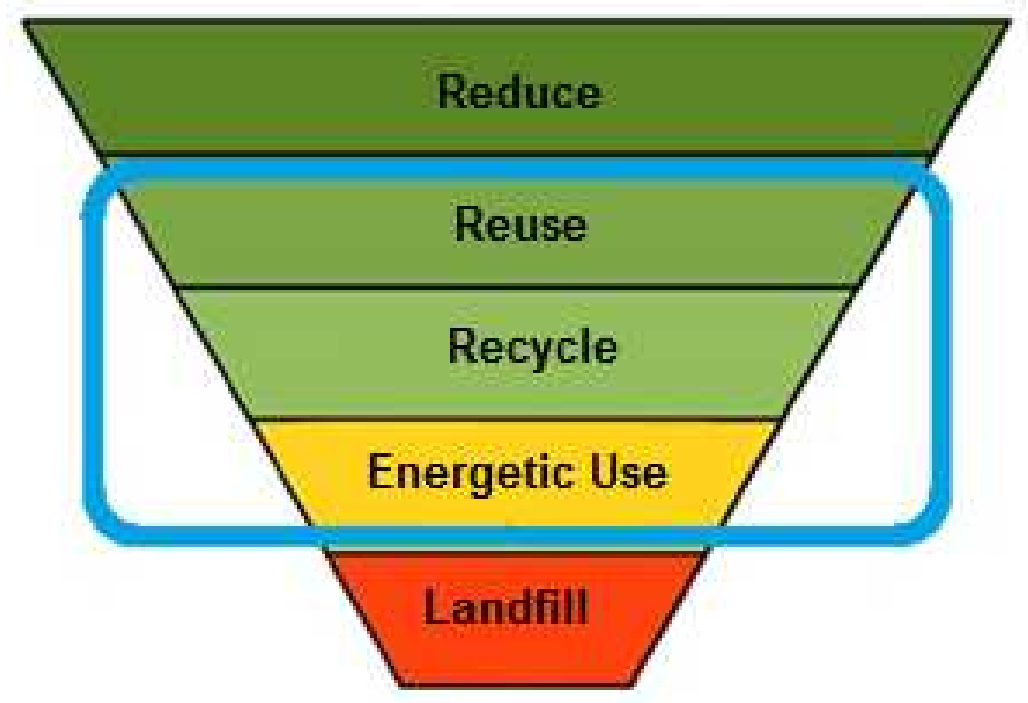

Fig. 3. Hierarchical Strategy of ISWM Source: Martínez and Ruiz (2015) 


\section{Discussion: Outlook of the Management for the City of Bogota}

According to the Integral Plan of Solid Waste Management in Bogota (capital of Colombia), between 5,000 and 6,000 tons arrive daily at the Doña Juana landfill; of this amount, $64 \%$ are organic waste and $36 \%$ inorganic; $18.7 \%$ of in organics are plastics and rubbers and $8.2 \%$ are paper and cardboard (Martínez Sepúlveda and Alberto, 2013). The remaining fraction can become a valuable material (in whole, if separated at source), which when disposed of at a landfill begins its process of degradation according to its physical and chemical characteristics, i.e., it can take between one and fifty years or more. In addition to this, thousands of people derive their livelihood recovering from the disposal line about 1,200 tons/day (in addition to the disposition in landfill) with clear inefficiencies in logistics, clear social level needs and benefits in environmental matters.

In the technology parks for the utilization of waste from developed countries, different waste fractions are handled through different lines of use, observing the needs of the environment and the actual conditions of implementation, in search of added value (Martínez Sepúlveda and Alberto, 2013); in some cases, the residues are referred to the generation of energy through processes of Waste to Energy; in other cases, the lines are separated and converted into soil improvers, or recyclable materials (recycled raw material generationRRM), or materials to dispose.

\section{The Current Management of Solid Waste in Bogota,} Years 2010 to Present

In recent years, two trends have marked the management of solid waste in Bogota: The implementation of the measures contained in the District Recycling Plan and the bidding process for the operation of the Doña Juana landfill and collection and transport of ordinary solid waste; Both trends have high importance for each and every one of the 11,139 recyclers in Bogotá (according to data from Javeriana University-UAESP).

\section{District's Recycling Plan}

Two things should be noted about the District's Recycling Plan: One, concerning the completion of the first "pilot" recycling park called La Alquería; the other, carrying out activities on the use of organic waste in the District (Agreement 344 2010).

Regarding the first experience, it should be mentioned that the main objective of the District Recycling Plan of 2004 was "...ensuring that the city takes advantage of the waste it produces, forging an environmentally responsible handling of these, including the population of recyclers and generating an added value to the supply chain ..." and from there four fronts were created: (i) Source separation, (ii) selective collection route, (iii) recycling parks and (iv) social component aimed at recyclers. The District oversight in a report in 2008 estimated that the budget that would be allocated regarding the implementation of this plan would surpass 29,000 million pesos; the activity in the recycling park of La Alquería was developed inconsistently for about five years, reaching a maximum handling of 300 tons/month of waste and today, it is not articulated with the special routes for usable materials covering a fraction of the area of the city.

Moreover, the UAESP for the management and collection of reusable waste, designed and conducted a series of activities aimed at source separation of organic and recyclable waste. Agreement 344 of 2008 promotes cultural transformation of citizen's habits against the management of organic waste and its possible use. The program for the comprehensive management of solid organic waste in Bogota DC has among other purposes the promotion and guarantee of fundamental rights to life, health and sanitation, proposing models of productivity and job creation. To achieve this, there have been pilot tests with the Industrial University of Santander (UIS) in order to evaluate alternatives for composting of the organic fraction of Municipal Solid Waste (OFMSW) and the variables associated with this process (Fig. 4).

Tender for the Operation of Doña Juana Landfill and Waste Collection and Transport Until 2012

Another initiative for recovery of solid waste by the recyclers of the city driven by UAESP was that given with tender 001 of 2010 "Contracting through the modality of concession the Integral Administration, Operation and Maintenance of the Doña Juana Landfill-DJL of Bogota DC Colombia, in its components of final disposal of solid waste and leachate treatment, with treatment and use options of waste entering the DJL, arising from the ordinary waste collection service". All the above, in accordance with the legal, technical and financial parameters contained in this specification and its technical annexes; The process culminated in the consortium being awarded and allowed a share of close to $1 \%$ of a second level association of recyclers (Federation of Independent Recyclers of ColombiaFEDERINCOL), which did not meet the expectations of stakeholders and left a feeling of apparent but not effective inclusion in the consortium that will operate the DJL for 11 years. 

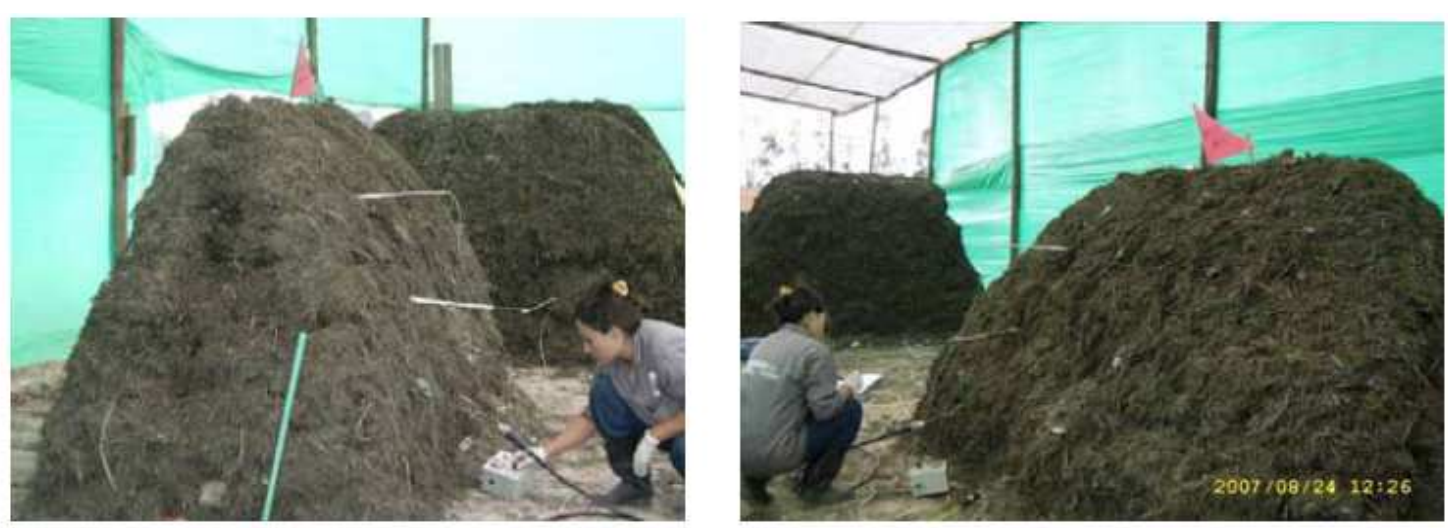

Fig. 4. Photos of composting tests conducted with OFMSW; Source: Martínez and Uribe (2013)

On the other hand, taking into account that Bogota has a garbage collection system operated by four concessionaires which serve a total of 1,760,210 users, which dispose in the DJL 185,910 tons per month, in 2011 the UAESP began the process of public bidding No. 001 of 2011, whose objective was “... awarding under the figure of Exclusive Service Areas, the provision of Domiciliary Waste Collection Public Service in the city of Bogota DC Colombia, in its components of collection, sweeping, cleaning of roads and public areas, grass cutting, tree pruning in public areas and transportation of waste to the final disposal site and all the activities of financial, commercial, technical, operational, educational and administrative type that this entails...". In this tender natural or legal persons interested in forming a promise of future society could participate in the selection process, in the form of a single object public service company, along with a partnership with second level Recyclers of those previously selected by the UAESP.

In the specifications of the tender 001 of 2011 is, as well as in many elements of the public policy of the past two years, the inclusion of Recyclers, in order to allow UAESP compliance with judgment T-724 of 2003 and Writs No. 268, 298 and 355 of 2010 handed down by the Honorable Constitutional Court and including all recyclers of trade $(11,200$ according to the census conducted in 2010) as shareholders in that tender.

The approach was that recyclers would continue collecting the material in the city supported by concessionaires and a Recycling Fund would be established to support and return resources to users as an incentive for source separation.

The inclusion involved a sufficiently large disclosure process so that all organizations of second level recyclers operating in the city of Bogotá, DC, sent to the Unit the legal documents evidencing their constitution with the competent authority with a minimum of one (1) year prior to the date of publication of the specifications draft and that since its constitution, its purpose has been to bring together organizations of recyclers of first level, made up of recyclers (natural persons) in conditions of vulnerability.

\section{The Overview from 2012 to This Day}

In December 2012, the Mayor of Bogota decided to create a public cleaning company, as it existed 30 years ago; the aim was to effectively link the base recyclers and collectors, in order to comply with the rulings of the honorable court, but in addition, stop the excessive payment of the service of collection, transportation, street cleaning and beautification of public areas that was being awarded to private parties, under the bidding scheme described above.

The new company called "Aguas de Bogota" has been operating since then and to date about $55 \%$ of the territory of the Capital and subcontracts private cleaning companies to do the work in the rest of the city; it had to purchase new equipment for their activities and due to the urgency of the process, initially there were shortcomings in the provision of service in some areas of the city. Three years after this, the company continues to provide the service, they reduced less than $10 \%$ of the costs associated with the activities of collection, sweeping and cleaning for citizens and social inclusion in the company allowed about 1,000 people to leave activities of reusable waste collection under unworthy conditions (without safety equipment, on the street, without pay) for legal working conditions.

The great challenge presented today is the implementation of the program called "Zero Waste", in which environmental education, waste separation in homes and increasing the fraction of recoverable waste would increase over three years, at the same time in which business processes for the formalization of the Informal Waste Collector's companies are developed. This process has been going on, but beyond acknowledging a fraction of the fee on behalf of the "use of materials" to formalized recycler's companies, the figures of utilization have not changed significantly and 
the road for citizens to separate at the source or for the amounts of waste per day to be used to increase still looks long and needs a lot of management.

\section{Why will we do? Innovation and Research for the Solid Waste Management}

Overcome the "supply the basic needs" period in the waste management, the new century requires for the city the analysis of all the possibilities of the beneficial use of the MSW; besides the marketing of recyclable materials and compost (Dustano, 2014) or earthworm production for the OFMSW (Gómez and Jenny, 2012), the solid waste has multiple valorization options such as energy (Rodriguez and Luis, 2014), biofuels of second generation production (MME, 2007; 2012; Montoya and Nancy, 2012), animal feed production, urban mining, recycled rain material and others. The innovation and the research in universities are the principal origin for the new alternatives, with one premise: The waste should be converts in resources.

For example, in the Solid Waste Research Line of the Universidad EAN (Colombia), with students of the Solid Waste Management specialization and collaboration of the Universidad de Castilla-La Mancha (Spain), they researched about the use of OFMSW for the Bio alcohols production (UCS, 2014), with laboratory proves and quantitative methodology. An anaerobic fermentation with Saccharomyces cerevisiae for industrial use and a controlled fermentation (Fig. 5) with monitoring parameters as $\mathrm{pH}$, temperature, $\mathrm{O} 2$ concentration, Total Suspend Solids (TSS) and Volatile Suspend Solids (VSS), using standard methods from APHA (1998) (Norms 2540 D and 2540 E), can be obtain a $4 \mathrm{~g}$ of $\mathrm{L}^{-1}$ bio alcohol production efficiencies.

The contributions of researchers to the issue of solid waste must focus in the prevention, based in the circular economy or Cradle to Cradle ${ }^{\circledR}$ models. With a strong development in a resources management (and not in the waste management) is possible that landfills life time will be large (more than the five to ten years that is the actual average life time) and, more important, the construction of new valor chains and the contribution of the shared value in the society will be real.

If we try to improve our knowledge about our waste/resources, the possibility of ti increase capacities on the subject of waste management in Colombia and the possibility of main -generation solutions will increase, and we will have projects with public/private companies in so many related areas; without diminishing the importance of sanitation services and basic sanitation systems, the future of waste management in Latin America requires the transfer and development of knowledge that can be done in research centers, as well as the involvement of multiple actors with a view to a real application of the concept of sustainable development to the issue of waste.

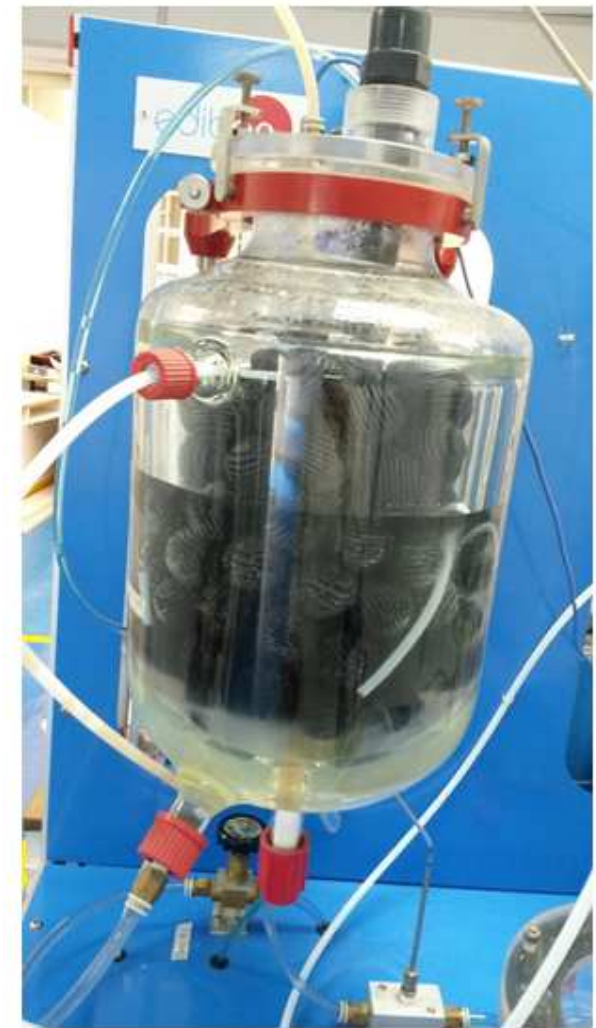

Fig. 5. Photo of fermentation system Tests with OFMSW Source: Martínez and Ruiz (2015)

\section{Conclusion}

In Latin America is necessary to evaluate different options for the management and use of the Municipal Solid Waste (MSW); with almost 600 millions of people and with an organic fraction of MSW higher than 54\%, requires beneficial uses of Municipal Solid Waste for a successful sustainable development of the countries.

In order to generate solutions to this situation, the options for to change the "disposal method" to the "use and value resources method" should be completely integrated in the waste management plans of the cities. Not only the landfill option is the target, the innovation and research are a really option, from the Research centers and Universities.

Bogota, as a capital city in Colombia, has a big challenges in waste management; not all is clear in the master plan of the city, because the discussion between public or private service, the interest on incorporate the informal waste pickers or the best way to incentive the eco design and the recycle into the companies and the citizens. But, the Bogota situation is not different to the others cities and municipalities in Latin America and is necessary a lot of engineers, designers and social actors for to discover the suitable plan for the waste management. 
The results of the Universidad EAN Studies contribute to the innovation and research about solid waste in Bogota, because they obtain Bio alcohol in adequate proportions for to do a pilot plant proofs, using a modified fermentation process. This work and others from research centers and universities will can to support the future of the waste management, now under a new vision: The resources management.

\section{Acknowledgement}

Special acknowledgments to the students of Solid Waste Management Specialization and all the researchers that worked in the past five years in the waste management research line in the Universidad EAN (Colombia) for all their contributions to the waste knowledge.

\section{Ethics}

This article is original and contains unpublished material. The corresponding author confirms that all of the other authors have read and approved the manuscript and no ethical issues involved.

\section{References}

APHA, 1998. Standard Methods for the Examination of Water and Wastewater. 20th Ed., American Public Health Association, Washington, DC.

Dustano, T., 2014. Analysis of technical conditions for the creation of a company that handles organic waste from Paipa, Duitama, Sogamoso and Tunja municipalities. Final research report to obtain the title of specialist in solid waste management, Universidad EAN. Bogota.

Gómez, C. and M. Jenny, 2012. Analysis of variables to determine the technical and economic feasibility of obtaining earthworm meal from organic waste. Final research report to obtain the title of specialist in solid waste management, Universidad EAN. Bogota.

Lozano, S., J.A.M. Sepúlveda and N. Montoya, 2014. Análisis preliminar de la obtención de bioetanol a partir de la fracción orgánica de Residuos Sólidos Urbanos. Revista ACODAL, 235: 39-42.
Martínez Sepúlveda, J.A. and N.J.M. Gómez, 2013. Análisis preliminar de la viabilidad de obtención de bioetanol a partir de la fracción orgánica de los residuos sólidos urbanos. Producción Limpia, 8: $72-84$.

Martínez Sepúlveda, J.A. and U.J. Alberto, 2013. Evaluación de la implementación de un parque tecnológico en Bogotá. Cuaderno de Investigación, Universidad EAN, Bogotá.

Martínez Sepúlveda, J.A., 2012. Propuesta para el desarrollo de un spin off en residuos sólidos en Bogotá-Colombia. Revista Ciencia Tecnol. Ejército. 3: 64-75.

Martínez Sepúlveda, J.A., 2013. Use and valorization of Organic Fraction of municipal solid waste in Colombia for sustainable development. Revista Ontare., 1: 243-254.

Martínez, J.A. and L. Ruiz, 2015. Modelo de gestión cero residuos en relleno sanitario para una unidad de manufactura mediana. Asociación Colombiana Ingeniería Sanitaría Ambiental Revista, 238: 30-40.

Martínez, J.A., N. Montoya and M. Sierra, 2014. Energía del futuro: Bioalcoholes a partir de Residuos Sólidos Urbanos (RSU). Revista EAN, 77: 64-81.

MB, 2012. What a waste: A global review of solid waste management. Mundial Bank, Washington.

MME, 2007. El programa de biocombustibles en Colombia. Ministerio de Minas y Energía.

MME, 2012. Evaluación del ciclo de vida de la cadena de producción de biocombustibles en Colombia. Ministerio de Minas y Energía.

Montoya, G. and J. Nancy, 2012 Analysis of the Feasibility of obtaining bioethanol from organic fraction of Municipal Solid Waste (MSW). Final research report to obtain the title of specialist in solid waste management, Universidad EAN. Bogota.

Rodriguez, P. and A. Luis, 2014. Technical feasibility of producing biogas from the organic fraction of urban solid waste. Final research report to obtain the title of specialist in solid waste management, Universidad EAN. Bogota.

UCS, 2014. Turning agricultural residues and manure into bioenergy. The Union of Concerned Scientists. 